J. Clin. Chem. Clin. Biochem.

Vol. 23, 1985, pp. $683-689$

\title{
The Variable Reagent Blank: Protein Determination as a Model
}

\author{
By D. Bozimowski', J. D. Artiss ${ }^{2}$, and B. Zak ${ }^{1,2}$ \\ Departments of Biochemistry ${ }^{1}$ and Pathology ${ }^{2}$, Wayne State University School of Medicine and Detroit Receiving \\ Hospital/University Health Center ${ }^{2}$, Detroit, Michigan, USA
}

(Received January 3/May 6, 1985)

\begin{abstract}
Summary: Three total protein assays were analyzed to determine the extent of deviation encountered when a constant measured reagent blank is compared to a continuously decreasing true reagent blank. This blank effect owes its regressive nature to the consumption of the active reagent ingredient by the protein reactive species, variably and sometimes, with certain reactants, nonlinearly in the presence of increasing protein concentrations. However, the blank effect of interest here is apparent only when the reagent and the reagentprotein complex present overlapping spectra and therefore absorb at the wavelength of measurement. Thus it was found that while the biuret and the Coomassie brilliant blue assays produced pronounced differences in the variable true reagent blanks, the Folin-Ciocalteau reaction did not develop a deviation from the true blank since the reagent blank does not absorb to any extent at the assay wavelength. In this manner, the latter procedure could serve as a marker against which the former two blank reactions can be shown to display relatively excessive deviations.
\end{abstract}

\section{Der unterschiedliche Reagenzienleerwert: Proteinbestimmung als Modell}

Zusammenfassung: Drei Methoden zur Bestimmung von Gesamtprotein wurden untersucht, um das Ausmaß der Abweichung zu bestimmen, das auftritt, wenn ein gemessener konstanter Reagenzienleerwert mit einem kontinuierlich abfallenden wahren Reagenzienleerwert verglichen wird. Dieser von der Analytkonzentration abhängige Leerwerteffekt beruht auf dem Verbrauch von reaktiven Bestandteilen des Reagenz durch die reaktive Proteinspezies. Er ist in Gegenwart steigender Proteinkonzentrationen variabel und mit bestimmten Reaktionspartnern manchmal nicht-linear. Der hier interessierende Leerwerteffekt ist jedoch nur zu beobachten, wenn Reagenz und Reagenz-Protein-Komplex sich überlappende Absorptionsspektren aufweisen und deshalb beide bei der Meßwellenlänge absorbieren. So wurde gefunden, daß zwar das Biuret- als auch das Coomassie-Brilliant-Blau-Verfahren ausgeprägte Differenzen in den variablen wahren Reagenzienleerwerten verursachten, die Folin-Ciocalteau-Reaktion aber keine Abweichung vom wahren Leerwert aufwies, da hier der Reagenzienleerwert bei der Meßwellenlänge nicht absorbiert. Auf diese Weise kann das Folin-CiocalteauVerfahren als Prüfmethode dienen, die relativ erheblichen Abweichungen der Leerwertreaktion der beiden anderen Methoden aufzuzeigen.

\section{Introduction}

In some analytical procedures, the contribution of the reagent blank is of a constant nature. Except for circumstances such as those involving inorganic ion measurement in which the analyte of interest may be a contaminant of the water of the blank, subtraction of the reagent blank can be a minor consideration (1). However, if the active constituent of the reagent blank has a spectrum overlapping that of the equilibrium reaction product generated and is a consumable in creating the latter, the true reagent blank is actually regressive in the final measurement. Thus, 
if the conventional subtraction is used for a constant and highly coloured reagent blank from a reaction in which a variable amount of the active ingredient of the reagent is to become a part of the equilibrium reaction, then true absorbance is not achieved for the product of interest $(2,3)$. The calibration slope used then to measure product may be considerably lower than the theoretical true slope. Some attention to this point has previously been described for calciumcresolphthalein in which both reagent blank and the calcium complex show similar if not identical spectra (2).

A blank phenomenon has been reported for competitive protein binding assays to determine steroids, in which either a positive or negative blank effect was elicited in an unpredictable manner such that arithmetic manipulation would not provide an adequate correction (4). However, little if any attention to the blanking aspect of a reaction has been devoted to protein measurements with commonly used reactants such 'as biuret or Coomassie brilliant blue reagents. Inasmuch as both of these reactants are strong spectral absorbers in the blank matrix, and each is consumed during the reaction process, a true calibration slope cannot be generated by simple subtraction because the strongly-colored, measured reagent blank is constant in its spectral character and must therefore always be higher in concentration and therefore stronger in absorbance than it could possibly be in the final equilibrium reaction. It is obvious then, that if the reagent blank effect is treated as a static instead of a dynamic one, as it is, then deviation from the true absorbance for either standards or samples will increase in direct proportion to the protein concentration as a function of the regressing blank absorbance obtainable from the reagent itself.

We undertook this study in order to investigate the apparent variable regressive nature of protein reagent blanks. The spectrophotometric characteristics of the biuret, Coomassie brillant blue and the Folin-Ciocalteau reagents provided the experimental data to investigate the blank effects of these protein reagents all of which are commonly used in clinical and research biochemical laboratories. These reactants were also chosen because each reactant varies in its abilities to assay mixtures of proteins (5). Biuret reagent reacts quite similarly with both albumin and globulins, Coomassie brilliant blue reagent reacts more strongly with albumin than globulins while the Folin-Ciocalteau reagent reacts more strongly with globulins than with albumin on a weight to weight basis. It will be demonstrated that although the theoretical calibration curves cannot be achieved in the face of a consumable and measured reagent constituent, still, if the blank regression follows a linear progression, any non-linearity in calibration derives from nonstoichiometry in the reaction of proteins under the conditions of the chosen reaction. In the latter case, the true reagent blank can be inferred, indeed proven, to be non-linear in effect even though, if measured alone, it obeys Beer's law.

\section{Materials and Methods}

Chemicals

Human serum albumin and Coomassie brilliant blue R-250 were obtained from Sigma Chemical Co. (St. Louis, MO). Potassium iodide, sodium hydroxide, sodium carbonate, cupric sulfate-pentahydrate and sodium-potassium tartrate (tartrate) were obtained from Mallinckrodt Inc. (St. Louis, MO). Ethanol $(95 \%)$; phosphoric acid and Folin-Ciocalteau phenol reagent were obtained from Fisher Scientific Company (Pittsburgh, PA).

\section{Apparatus}

A Beckman Model 25 (Beckman Instruments, Fullerton, CA) spectrophotometer and recorder were used to generate all spectra and a Gilford Model 300N (Gilford Instrument Laboratories, Inc., Oberlin, $\mathrm{OH}$ ) was used to determine calibration curves and true reagent blank data.

\section{Reagents}

Biuret reagent

a) Prepare the blank reagent in $\mathrm{NaOH}(0.6 \mathrm{~mol} / \mathrm{l})$ to contain $14 \mathrm{~g}$ of tartrate and $5 \mathrm{~g}$ of $\mathrm{KI}$ per liter.

b) Prepare the copper-biuret reagent in blank reagent to contain from $1.0 \mathrm{~g}$ to $6.0 \mathrm{~g}$ of $\mathrm{CuSO}_{4} \cdot 5 \mathrm{H}_{2} \mathrm{O}$ per liter.

\section{Coomassie brilliant blue reagent}

a) Prepare the blank reagent to contain $50 \mathrm{ml}$ of ethanol and $100 \mathrm{ml}$ of $\mathrm{H}_{3} \mathrm{PO}_{4}$ per liter of water.

b) Prepare Coomassie brilliant blue reagent to contain from $10 \mathrm{mg}$ to $100 \mathrm{mg}$ dissolved in $50 \mathrm{ml}$ of ethanol and $100 \mathrm{ml}$ $\mathrm{H}_{3} \mathrm{PO}_{4}$ per liter of water.

\section{Folin-Ciocalteau reagent}

a) Prepare the alkaline tartrate reagent in $\mathrm{NaOH}(0.1 \mathrm{~mol} / \mathrm{l})$ to contain $20 \mathrm{~g}$ of $\mathrm{Na}_{2} \mathrm{CO}_{3}$ and $0.5 \mathrm{~g}$ of $\mathrm{NaK}$-tartrate per liter.

b) Prepare the copper reagent to contain $1 \mathrm{~g}$ of $\mathrm{CuSO}_{4} \cdot 5 \mathrm{H}_{2} \mathrm{O}$ per liter of water.

c) Prepare the working reagent as: 90 volume parts of alkaline tartrate reagent +10 volume parts of copper reagent.

d) Prepare Folin-Ciocalteau phenol reagent dilutions to contain from $2.5 \mathrm{mmol}$ to $20.0 \mathrm{mmol}$ per liter of water. 


\section{Procedures}

\section{Biuret reaction}

To $2.0 \mathrm{ml}$ of biuret reagent add $100 \mu \mathrm{l}$ of protein solution. Mix and allow to stand for $30 \mathrm{~min}$ at room temperature. Read the absorbance of the developed colour against the blank reagent or the copper-biuret reagent at $540 \mathrm{~nm}$ and scan from 700 to $400 \mathrm{~nm}$.

\section{Coomassie brilliant blue reaction}

To $1.0 \mathrm{ml}$ of Coomassie dye add $100 \mu$ l of protein solution. Mix thoroughly and let stand for $5 \mathrm{~min}$ at room temperature. Read the absorbance of the developed colour against the blank reagent or the Coomassie brilliant blue reagent at $595 \mathrm{~nm}$ and scan from 800 to $400 \mathrm{~nm}$.

\section{Folin-Ciocalteau reaction}

To $3.0 \mathrm{ml}$ of working reagent add $60 \mu \mathrm{l}$ of protein solution. Mix well and allow to stand for $15 \mathrm{~min}$ at room temperature. Add $30 \mu \mathrm{l}$ of a Folin-Ciocalteau phenol dilution and mix immediately. Allow to stand for $30 \mathrm{~min}$ at room temperature. Read the absorbance of the developed colour against the working reagent with or without phenol at $730 \mathrm{~nm}$ and scan from 800 to $350 \mathrm{~nm}$

\section{Results and Discussion}

In order to establish the problem and to describe its ramifications, the spectra of the blank reagents and their protein products scanned against a reagent blank or water blank were graphed for the Coomassie brilliant blue and biuret reactions. Because the FolinCiocalteau reagent has no detectable spectrum in the range of measurement of the heteropoly blue reduction product, this reaction was deemed unnecessary for further spectral analysis. However, its blank reaction will be shown later in the discussion.

The biuret spectral results are presented in figure 1. On the left of this figure, the characteristic biuret spectra for several concentrations of protein $(\mathrm{g} / \mathrm{l})$ are illustrated when the reaction for each is subtracted from a reagent blank. On the right of the figure, the biuret protein spectra for the same solutions are shown for scans against water. Looking at the right side of the figure, an important consideration is apparent from inspection of these spectra in terms of the changing position of the peak maxima. Spectral response at the biuret measuring wavelength of 540 $\mathrm{nm}$, indicated by the arrow, gradually approaches the correct peak wavelength as the protein concentration increases, although at the concentrations tested, the peak of the more concentrated protein solution is still not quite at $540 \mathrm{~nm}$. This phenomenon is a graphic representation of the increased consumption of the copper reagent with an increase in protein concentration. Furthermore, the wavelength shift toward $670 \mathrm{~nm}$, the reagent blank peak responses, yields a disproportionate decrease in absorbance at $540 \mathrm{~nm}$

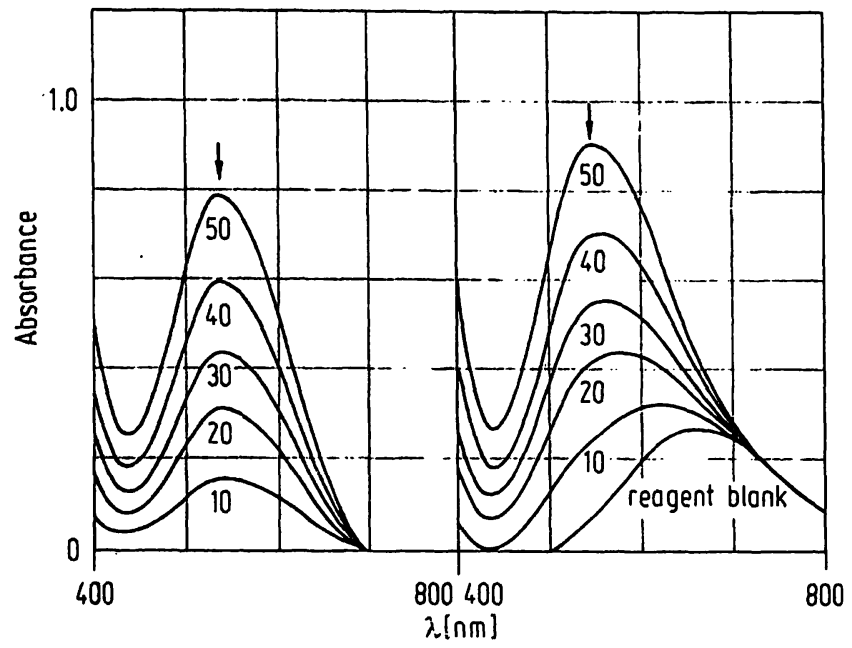

Fig. 1 left: Biuret protein spectra (scanned against reagent blank) at albumin concentrations of $50,40,30,20$, and $10 \mathrm{~g} / \mathrm{l}$.

right: Biuret protein spectra scanned against water at albumin concentrations of $50,40,30,20$ and 10 $\mathrm{g} / \mathrm{l}$ and the reagent blank $(\mathrm{Cu}=3.0 \mathrm{~g} / \mathrm{l})$ scanned against water.

with decreasing protein concentrations. The extent of this variably regressing blank is graphically depicted in figure 2.

The spectrophotometric representation of the regressing nature of a consumable, coloured and reactive reagent constituent is illustrated for the biuret reagent in figure 2 (left). The spectra shown here were obtained from the biuret reagent in an analytical circumstance in which the variable was the copper of the reagent while the constant was the matrix of the

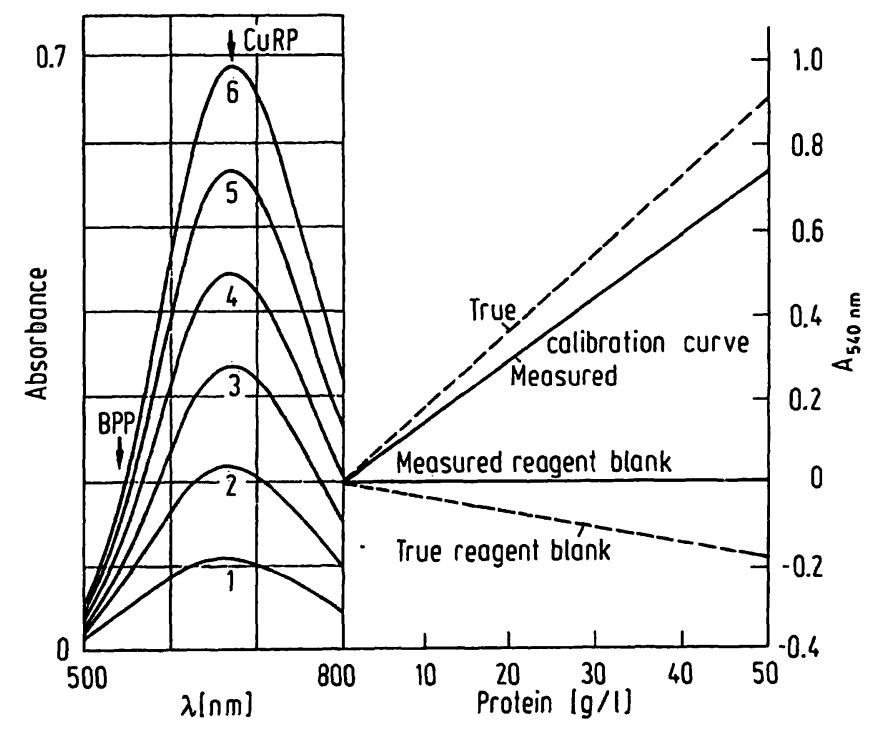

Fig. 2 left: Biurct reagent spectra at copper concentrations of $6.0,5.0,4.0,3.0,2.0$ and $1.0 \mathrm{~g} / \mathrm{l}$. The copper reagent peak (CuRP) and Biuret protein peak (BPP) are indicated by the arrows.

right: The deviation of the measured reagent blank from the true reagent blank is plotted against increasing human serum albumin. The effect of this deviation on the measured calibration curve is shown as the true calibration curve lor the biurct reagent. 
reagent. The strength of the spectral background character of this solution is obvious from both the copper reagent peak (CuRP) maximum readings at $670 \mathrm{~nm}$ as well as the biuret protein peak (BPP) readings at $540 \mathrm{~nm}$ on the side of the spectra representing but a portion of the peak reading. The biuret protein peak at $540 \mathrm{~nm}$ is the absorbance of the measured reagent blank for a specific copper concentration for all quantities of protein reacted.

In figure 2 (right) is the graphic information describing the extent of deviation of a true reagent blank as a function of consumed copper. If one sets the measured reagent blank at $0.0 \mathrm{~A}$ as shown, it is obvious that the true reagent blank is regressive, indicating that the measured calibration curve is caused to have a lower slope than one should obtain using the true reagent blank for then the true calibration curve slope shown would be the result. A close approximation to the slope of the true reagent blank can be obtained from the determination of protein by the biuret reaction using an ion exchange method (6). This fixed the ratio of copper to protein by weight to 10.3 to 1 in keeping with the much earlier findings of $\mathrm{Mehl}$ et al. (7) using a continuous variation plot. A more empirical but simpler approach was actually used to obtain the true reagent blank curve for this graph. The protein-biuret complex was read against the measured reagent blank. Then the same complex was read against a biuret reagent blank containing no copper. In effect, at this wavelength, this could be water. When the first reading was subtracted from the second reading, it provided a measure of the quantity of copper used up in generating the protein complex. By subtracting this value from the copper contained in the measured reagent blank, the residual true reagent blank could be derived. Inasmuch as the reaction of copper with protein follows a stoichiometric progression with increasing concentrations of protein and the spectral characteristic of the copper reagent itself is linear at the wavelength of the copper-protein complex, then the resultant finding of the measured calibration curve is that it should be linear as well. The spectra of varying concentrations of albumin and globulin with biuret has been published earlier. Therefore, except for the mild decrease in measured absorbance obtained owing to true blank regression, little harm ensues to the measurement. There seems to be no real advantage to obtaining the true calibration curve in this instance by calculation as an aid to the analytical measurement. However, it is an interesting enough phenomenon to warrant further investigation (8). Inadequate consideration has been given to this phenomenon in the literature thus far.
A similar spectrophometric study was then performed with Coomassie brilliant blue, a more sensitive protein reactant widely used in analytical biochemistry. The spectra obtained for the Coomassie brilliant blue reactions at various protein concentrations scanned against a reagent blank are shown in figure 3 (left). The nonlinearity of the calibration curve is evident at higher protein concentrations between 0.8 and 1.0 $\mathrm{g} /$ l. Figure 3 (right) illustrates the spectra obtained for the same protein concentrations when the reaction is scanned against a water blank. The protein measuring wavelength of $595 \mathrm{~nm}$ is indicated by the arrow. In contrast to the biuret reagent, the increased consumption of Coomassie brilliant blue can be visualized as a decrease in absorbance at the second reagent peak of $465 \mathrm{~nm}$ as well as the hypsochromic shift toward the measuring wavelength at $595 \mathrm{~nm}$.

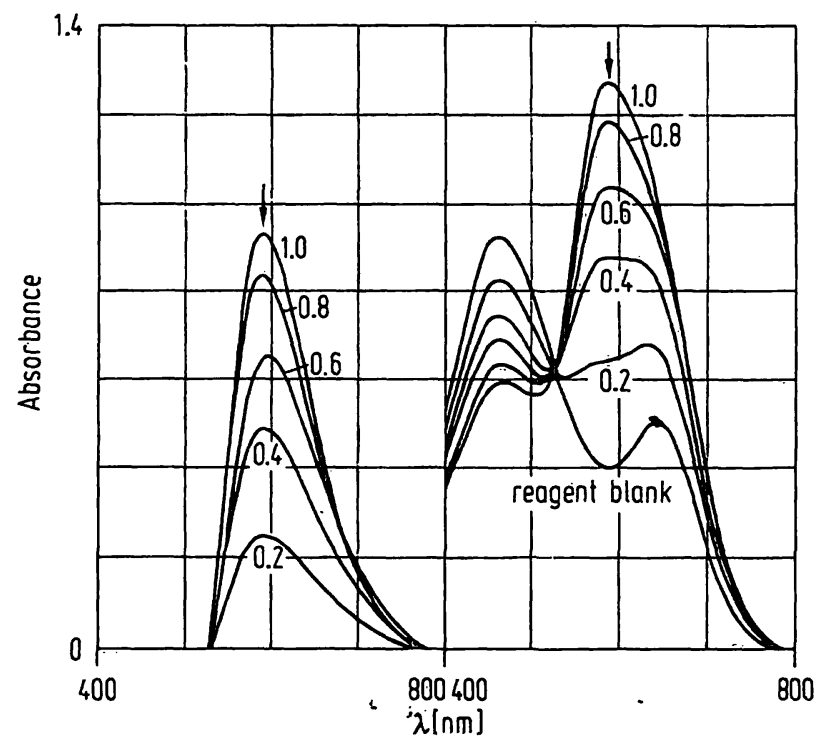

Fig. 3 left: Coomassie brilliant blue protein spectra scanned against reagent blank at albumin concentrations of $1.0,0.8,0.6,0.4$ and $0.2 \mathrm{~g} / \mathrm{l}$.

right: Coomassie brilliant blue protein spectra scanned against water at albumin concentrations of 1.0, $0.8,0.6,0.4$ and $0.2 \mathrm{~g} / \mathrm{l}$ and the reagent blank (Coomassie brilliant blue $=100 \mathrm{mg} / \mathrm{l}$ ) scanned against water.

The regressing nature of the Coomassie brilliant blue reagent blank is evident here as with the biuret blank.

In figure 4 (left), the regressing calibration characteristics are described by the spectra of the reagent at varying dye concentrations each prepared in a constant reagent matrix. There are two peaks obtained for this solution with a major one at $465 \mathrm{~nm}$ and a minor one at $645 \mathrm{~nm}$. The measuring wavelength is $595 \mathrm{~nm}$ in a spectral trough between the two peaks. Some idea as to the extent of the background is evident from these spectra while keeping in mind the fact that the reagent is a consumable. The spectra of varying concentrations of albumin and globulin with 
Coomassie brilliant blue achieving unequal reactions with these proteins on a weight basis has been published earlier (5).

Figure 4 (right) also shows the calibration data derived from the Coomassie brilliant blue reagent through reaction with human albumin standards. The measured reagent blank, once more, is an assumed constant value set at 0.0 absorbance in the figure. The measured calibration curve is somewhat nonlinear in keeping with the findings of several other published studies. The true reagent blank was studied by the method of continuous variations and these measurements indicated that the reaction was nonstoichiometric. As a result, the empirical but practical method described previously for the biuret reaction was used. In this second study, the Coomassie brilliant blue-protein complex was measured against the measured reagent blank and then against the matrix reagent that could be used for a protein blank

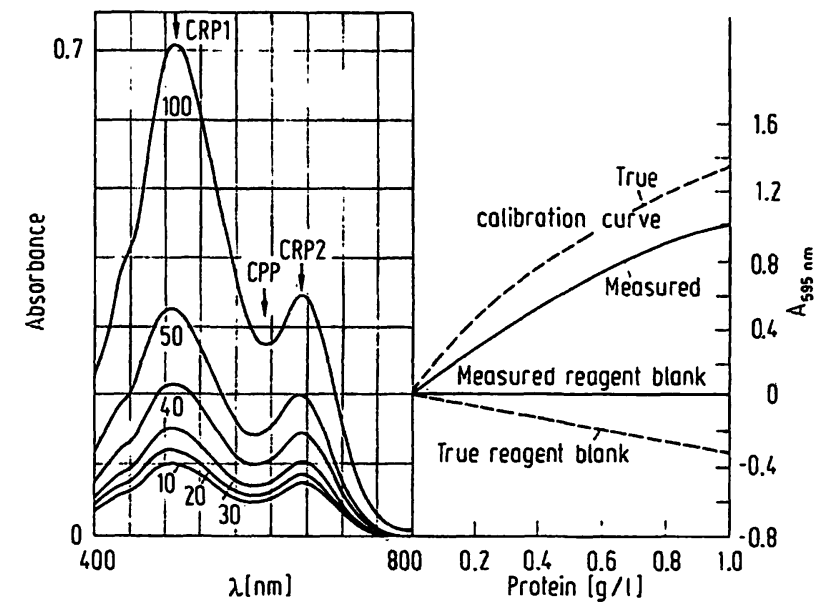

Fig. 4 left: Coomassie brilliant blue reagent spectra at Coomassie brilliant blue concentrations of $1.0,0.50$, $0.40,0.30,0.20$ and $0.10 \mathrm{~g} / \mathrm{l}$. The bimodal spectra elicit a major Coomassie brilliant blue reagent peak at $465 \mathrm{~nm}$ (CRP 1) and a minor Coomassie brilliant blue reagent peak at $645 \mathrm{~nm}$ (CRP 2). The Coomassie brilliant blue protein peak (CPP) is in a spectral trough.

right: The deviation of the measured reagent blank from the true reagent blank is plotted against increasing human serum albumin. The effect of this deviation on the measured calibration curve is shown as the true calibration curve for the Coomassie brilliant blue reagent.

solution. The difference between the readings was again an indirect measure of the Coomassie brilliant blue used up from which the residual Coomassie brilliant blue could be determined. The true calibration curve could then be calculated by the addition of this derived computation system and it manifests itself as the difference between the true calibration curve and the measured calibration curve. In a linear calibration system with a linear reagent blank a mathematical correction to true absorbance has been derived (8). By using the molar absorptivity of the product as numerator and the difference between molar absorptivity of product and reagent spectra at the measured wavelength as denominator, this factor becomes a multiplicand that will correct for the phenomenon of overlapped spectra. Inasmuch as no constant molar absorptivity is available in a non-linear calibration system, it would be more difficult mathematically to establish a single correction factor (8) then it would be were Beer's law to be obeyed. So, one weakness of such a corrective action is manifested by the non-linear calibration curve.

In contrast to the spectral results obtained for the biuret and Coomassie brilliant blue reagents, the Folin-Ciocalteau reagent itself is not a strong spectral absorber at or near the protein measuring wavelength. Figure 5 (left side) shows the portion of the spectra obtained between 800 and $400 \mathrm{~nm}$ when the

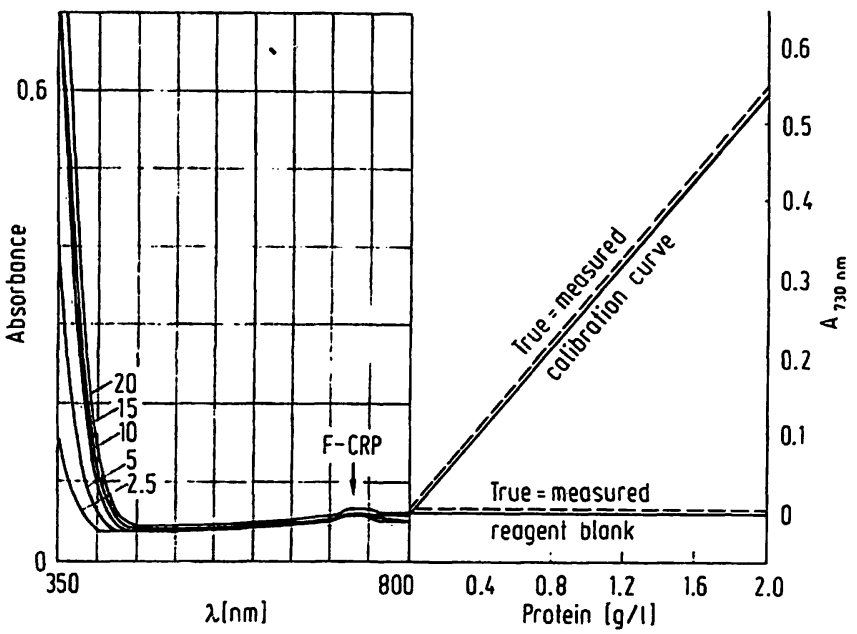

Fig. 5 left: Folin-Ciocalteau reagent spectra at Folin-Ciocalteau concentrations of $20,15,10,5$, and 2.5 $\mathrm{mmol} / \mathrm{l}$. The Folin-Ciocalteau reagent peak (FCRP) corresponds to the generated protein peak at $730 \mathrm{~nm}$.

right: The non interactive spectra of the Folin-Ciocalteau reagent indicates that the measured reagent blank is equal to the true reagent blank and thus the measured calibration curve equals the true calibration curve.

Folin-Ciocalteau concentration is varied while the matrix is held constant. Any spectral difference would manifest itself below $400 \mathrm{~nm}$ and that is certainly of no consequence in Folin-Ciocalteau protein measurements. As the oxidation of available protein sites occurs, more heteropoly blue complex is formed from the reagent itself. So this reaction differs from the other two in that the chromogen measured is only related to the protein by the reducing groups present and no protein complex is formed as in the case with the other two protein reagents. Thus, no significant 
difference in absorbances were obtained at the FolinCiocalteau protein peak (F-CPP) of $730 \mathrm{~nm}$ when the Folin-Ciocalteau reagent was varied while a definite increase occurred as the wavelength advanced towards the ultraviolet range and away from the measuring wavelength. However, one can see that there seems to be a small concentration of the mixed heteropoly blue complexes as a contaminant of the reagent that must be accounted for in blanking because it is the same complex as the species generated from protein.

Figure 5 (right side) was derived in the same manner as for the biuret and Coomassie brilliant blue reagents. No deviation of the reagent blank occurs at $730 \mathrm{~nm}$ with the Folin-Ciocalteau reagent on reaction with varying quantities of albumin. The measured reagent blank can be superimposed upon the true reagent blank. Therefore, the measured calibration curve equals the true calibration curve. Any contribution of the small amount of reduced reagent in the blank showed no measureable effect in the experiment. Obviously, the colour of the Folin-Ciocalteau reagent or lack of it, plays a major role in its independence of the subtracted blank effect. The blank reagent is a pale yellow colour while the protein-reacted reagent is a heteropoly blue. The peak wavelengths of these forms are sufficiently spread apart so as to be non-interactive. Thus, the FolinCiocalteau reaction appears to represent the ideal situation where the true blank equals the measured blank and appears to bear out the assumption that reagent blanks contain and reflect the true uncomplexed reagent present in a sample reaction vessel (9). This assumption implies that the non-reactivity can be accounted for and corrected by subtraction and indeed such is the case for the Folin-Ciocalteau reagent. However, from the data in figures 2 and 4 one can infer that this is not the case for the biuret or the Coomassie brilliant blue reagents.

The stoichiometric relationship between biuret-copper and protein concentrations have been investigated (6). They found that $1 \mathrm{~g} / 1$ of copper binds to $10 \mathrm{~g} / \mathrm{l}$ of albumin. Coomassie brilliant blue on the other hand, binds to protein in a non-stochiometric fashion (10). We have observed that $1.0 \mathrm{~g} / \mathrm{l}$ of Coomassie brilliant blue binds to an average of $1.5 \mathrm{~g} / 1$ of human serum albumin at equilibrium (unpublished data). If one assumes stoichiometric binding of human serum albumin to copper or Coomassie brilliant blue then the unreacted amount can be calculated based on the previous binding ratios. Initially, $3 \mathrm{~g} / \mathrm{l}$ of copper is present in the biuret measured blank and $0.1 \mathrm{~g} / \mathrm{l}$ of Coomassie brilliant blue is in its measured blank. Table 1 demonstrates that the calculated free copper or Coomassie brilliant blue dye remaining at equilibrium does not correspond to the constant measured blank. As the protein concentration increases the deviation of the measured blank from the true blank increases proportionately. This accounts for the observed variable true blank seen in figures 2 (left) and 4 (left). However, since Coomassie brilliant blue binds non-stoichiometrically, the calculated reagent consumption values are only indicative of a trend and not precise numbers.

Tab. 1. Calculated reagent consumption.

\begin{tabular}{|c|c|c|c|}
\hline \multicolumn{2}{|c|}{ Biuret assay } & \multicolumn{2}{|c|}{ Coomassie brilliant blue assay } \\
\hline $\begin{array}{l}\text { Human } \\
\text { serum } \\
\text { albumin }\end{array}$ & Free $\mathrm{Cu}^{1}$ & $\begin{array}{l}\text { Human } \\
\text { serum } \\
\text { albumin }\end{array}$ & $\begin{array}{l}\text { Free } \\
\text { Coomassie } \\
\text { brilliant blue } 2\end{array}$ \\
\hline$(g / l)$ & $(g / l)$ & $(\mathrm{g} / \mathrm{l})$ & $(g / l)$ \\
\hline 0.0 & 3.0 & $0: 00$ & 0.10 \\
\hline 1.0 & 2.9 & 0.02 & 0.08 \\
\hline 2.0 & 2.8 & 0.04 & 0.07 \\
\hline 3.0 & 2.7 & 0.06 & 0.06 \\
\hline 4.0 & 2.6 & 0.08 & 0.05 \\
\hline 5.0 & 2.5 & 0.10 & 0.03 \\
\hline 6.0 & 2.4 & & \\
\hline
\end{tabular}

1 Free $\mathrm{Cu}$ based on $1 \mathrm{mg} \mathrm{Cu}$ binds $10.3 \mathrm{mg}$ human serum albumin.

2 Free Coomassie brilliant blue based on $1 \mathrm{mg}$ Coomassie brilliant blue binds $1.5 \mathrm{mg}$ human serum albumin.

Our results indicate that some factors involved in protein assays may not be as well understood as previously thought. The variably regressing blank lowers both the biuret and Coomassie brilliant blue calibration curves since the reagent spectra overlap the final reaction spectra while the Folin-Ciocalteau reagent exhibits no overlap with the final protein reaction spectra. This blank effect can be overcome and accurate protein determinations can still be made but by empirical means. That is, as long as the standards and samples react in a similar manner then there is no practical importance to the true calibration curve. However, since the Coomassie brilliant blue assay and the Folin-Ciocalteau assay are subject to overestimation of certain protein constituents (5) and since the Coomassie brilliant blue dye also binds nonstoichiometrically to protein (10) careful evaluation of the protein assay to be used in the research or clinical laboratory must be made. 


\section{References}

1. Kloster, M. B. \& Hach, C. C. (1972) Anal. Chem. 44, $1061-1063$.

2. Clark, W. L., Baginski, E. S., Marie, S. S. \& Zak, B. (1975) Microchem. J. 20, 22-32.

3. Baginski, E. S., Marie, S. S., Karcher, R. E. \& Zak, B. (1982) Microchem. J. 27, 141-150.

4. Pizarro, M. A. \& Kolanowski, J. (1972) J. Steroid Biochem. 3, 349-356.

5. Bozimowski, D., Artiss, J. D. \& Zak, B. (1983) Microchem.

. J. 28, 285-293.

6. Doetsch, K. \& Gadsen, R. H. (1973) Clin. Chem. 19, 1170-1178.
7. Mehl, J. W., Pacovska, E. \& Winzler, R. J. (1949) J. Biol. Chem. 177, 13-21.

8. Kroll, M. H. \& Elin, R. J. (1985) Clin. Chem. 30, 1053 A.

9. Mason, W. B. \& Henry, R. J. (1974) Photometry and Spectrophometry. In: Clinical Chemistry: Principles and Technics (Henry, R. J., Cannon, D. C. \& Winkleman, J. W., eds.) pp. 24-25, Harper and Row, Hagerstown.

10. Bosshard, H. F. \& Datyner, A. (1977) Anal. Biochem. 82, 327-333.

Joseph D. Artiss, Ph. D.

Department of Pathology

Wayne State University

School of Medicine

Detroit, MI 48201

U.S. A. 


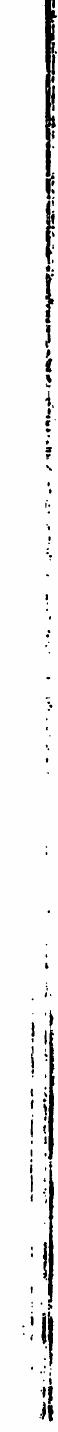

